\title{
Colonic mucus and mucosal glycoproteins: the key to colitis and cancer?
}

One of the more consistent features of ulcerative colitis is its tendency to affect the distal rather than the proximal colon yet many of the hypotheses for its aetiology have failed to take this into account. The distribution of colitis can most easily be explained by an interaction between the mucosa and some intraluminal agent that is secreted or released into the colon so rising in concentration from the proximal to the distal colon. One hypothesis consistent with this is that there may be an altered relationship between mucus and the mucus degrading enzymes that are secreted by some colonic bacteria. ${ }^{1}$

\section{Mucus and bacteria}

Mucus owes its properties to the presence of the mucus glycoproteins or mucins. These are heavily glycosylated and very large (molecular weight 2 $20 \times 10^{6} \mathrm{D}$ ). They should not be confused with mucopolysaccharides which are uronic acid containing substances like heparan and dermatan found in connective tissue. The mucin molecule bristles with oligosaccharide side chains the initial sugar of which is always $\mathrm{N}$ acetyl galactosamine $\mathrm{O}$-linked onto serine or threonine in the protein core (in contrast with the $\mathrm{N}$-linked oligosaccharide side chains that predominate in non-mucus glycoproteins). Onto this initial galactosamine may be attached up to 10 or more sugar moieties which can include $\mathrm{N}$ acetyl glucosamine, galactose, $\mathrm{N}$ acetyl galactosamine, fucose or the acid sugar sialic acid (usually as $\mathrm{N}$ acetyl neuraminic acid). These sugars have considerable variation in their linkage and branching which gives the oligosaccharide side chains greater heterogeneity than would be found in peptide chains of a similar length. These sugars either singly or in combination have blood group antigenicity. To a considerable extent in the proximal colon and universally in the distal colon the terminal sugar is replaced by the sialic acid $\mathrm{N}$ acetyl neuraminic acid and $\mathrm{ABO}$ antigens are therefore not expressed but other blood group antigens such as Lewis, I, i, T and Tn can be revealed by removal of distal carbohydrate and sialic acid. Colonic mucus is distinguished from mucus in the proximal intestine not only by its greater sialylation but also by its marked degree of sulphation. This probably occurs chiefly as ester sulphate present on glucosamine residues. It increases the charge of the mucus and therefore its tenacity and also greatly increases its potential to resist attack by bacterial enzymes. ${ }^{2}$ 
In a series of studies Hoskins and colleagues have shown that about $1 \%$ of the normal colonic flora are able to secrete glycosidases that allow these bacteria to use shed mucus as their sole energy source. ${ }^{3}$ They have so far identified two organisms capable of doing this: Ruminococcus torques and Bifidobacterium bifidum. ${ }^{4}$ It is not known whether there is any alteration in the frequency of these organisms in ulcerative colitis. Most bacterial glycosidases are exoglycosidases - that is, they are only able to act on the terminal sugar in a side chain. As much of the mucus in the colon has side chains terminated by sialic acid it follows that the bacteria have to produce a sialidase (neuraminidase) capable of breaking off the sialic acid before further degradation can proceed. There is a further problem here in that the sialic acids in colonic mucus commonly have $\mathrm{O}$ acetyl groups substituted at the $\mathrm{C} 4,7,8$ or 9 positions. (All mammalian sialic acids are either $\mathrm{N}$ acetylated or $\mathrm{N}$ glycolylated, the $\mathrm{O}$ acetylation occurs in addition to not as an alternative to $\mathrm{N}$ acetylation). The presence of these $\mathrm{O}$ acetyl groups, particularly at the $\mathrm{C} 4$ position, makes the sialic acid highly resistant to attack by sialidases. A bacterial $\mathrm{O}$ acetyl esterase ${ }^{5}$ therefore has to be present in addition to sialidase before further degradation can occur and the presence of ester sulphate on the glucosamine residues also necessitates the presence of an appropriate sulphatase. Studies by our own group and others have shown that normal faeces commonly contain the sialidases, $O$ acetyl esterases and sulphatases needed for initiation of mucus degradation in the colon $^{5-7}$ and that these enzymes are capable of acting on mucus as a substrate. ${ }^{8}$

Alterations in sialylation and sulphation of mucins and in the $O$ acetylation of the mucin sialic acids could all have important effects on the resistance of the mucus to bacterial enzymatic attack. Some indirect information about these aspects of mucus chemistry has been obtained using special histochemical stains. One combination of stains that has been particularly useful is high iron diamine together with alcian blue at $\mathrm{pH} 2 \cdot 5$. Both these stains are dependent on the differing charges conferred by the presence of the sulphate and sialic acid. High iron diamine stains the highly charged sulphated mucins brown while alcian blue at $\mathrm{pH} 2.5$ stains all acid mucins - that is, sialylated or sulphated mucins. In the left colon the usual pattern is for the deeper crypts to stain brown (sulphomucin) while the more superficial crypts contain non-sulphated sialomucins whereas in the right colon sulphomucins are found predominantly in the upper crypts. ${ }^{9}$ In active ulcerative colitis Filipe and colleagues have shown a relative diminution of sulphomucins together with a reciprocal increase in sialomucins. ${ }^{10}$ When interpreting the results of these histochemical studies it is important to realise that the sulphomucin containing goblet cells also contain sialomucin ${ }^{8}$ and very probably mucins that are both sialylated and sulphated on the same molecule. Replacement of the normal high iron diamine staining of crypts by alcian blue staining therefore simply implies loss of sulphation and not necessarily an increase in sialylation. Alkali treatment to remove the $\mathrm{O}$ acetyl groups has been used in combination with histochemical staining to give information about the degree of $\mathrm{O}$-acetylation of the mucin sialic acids. Using this technique Reid and colleagues have shown reduced $\mathrm{O}$ acetylation at the $\mathrm{C} 4$ position in ulcerative colitis."

It should follow from these histochemical abnormalities that the mucus in ulcerative colitis is likely to be more susceptible to bacterial enzymatic 
attack. To assess this more directly we performed studies in which the high iron diamine and alcian blue stains were used to examine semiquantitatively the state of sialylation and sulphation of mucus in biopsies from patients and controls after incubation of the biopsies in bacteria free filtrates of faecal homogenates. Using this technique we were able to confirm the desialylation and desulphation of rectal mucus by faecal enzymes but were unable to show any increased susceptibility to desialylation or desulphation of the rectal mucus in ulcerative colitis. ${ }^{8}$ The mucus in Crohn's disease was found to be particularly resistant to desialylation and this apparent 'toughness' of the mucus in Crohn's disease would fit well with the characteristic retention of mucus that is seen even in the presence of inflammation in this disease. The marked variation in substrate specificity between different bacterial glycosidases, sialidases and sulphatases means that we still cannot exclude the possibility that there may be a bacterial enzyme to which ulcerative colitis mucus exhibits greater susceptibility and further studies along these lines are needed particularly now that bacteria which produce mucus degrading glycosidases have been identified.

Even if the mucus/bacteria hypothesis for ulcerative colitis is incorrect the inhibition of the bacterial degradation of mucus, either by eradicating the bacteria themselves or by the development of non-toxic inhibitors of their mucus degrading enzymes could provide a new therapeutic approach in all conditions where the colonic mucosa is under attack. Possible therapeutic agents might include synthetic sulphated or sialylated carbohydrates which would act via competitive substrate inhibition, bactericidal agents such as bismuth compounds (which we are currently trying in colitis with promising early results) or antibiotics such as tobramycin ${ }^{12}$ that are not inactivated in faeces, unlike many of the antibiotics previously tried in colitis.

\section{Alterations in mucus biochemistry}

Alterations in mucus glycoprotein biochemistry may have consequences not only on its resistance to enzymatic attack but also on the physical properties of the mucus as a protective barrier. The oligosaccharide side chains of the mucin are particularly important in determining its physical properties so the demonstration by Clamp and colleagues that in active ulcerative colitis and Crohn's disease the side chains are considerably shortened ${ }^{13}$ may have important consequences for the function of the mucus even if this alteration is only occurring secondary to the disease process. A similar reduction in glycosylation of mucus has been found in colorectal cancer. ${ }^{14}$

The report that in ulcerative colitis there is selective depletion of one of six mucin subclasses (fraction IV) even when the disease is in remission ${ }^{15} 16$ aroused considerable interest. In these studies the mucins had been purified and then separated according to their charge by ion-exchange chromatography using a discontinuous salt gradient with six concentration steps. Mucins are notoriously difficult to purify and the interpretation of these studies depends on the purity of the preparation. We have found that colonic mucins purified by high performance gel filtration and subjected to ion exchange chromatography using a linear salt gradient elute as a bifid peak at a high salt concentration commensurate with their high degree of sialylation and sulphation ${ }^{17}$ and that use of a discontinuous salt gradient tends to artificially increase the number of mucin fractions. ${ }^{18}$ Similar ion- 
exchange profiles have been reported for colonic mucin by other groups..$^{190}$ Using this technique we have found no difference in the ion exchange profile of mucins from colitics and controls. ${ }^{17}$ Fraction IV may in fact have constituted the major mucin component and its depletion may reflect the reduced mucin content of the tissue. This interpretation is in keeping with the finding that there is no demonstrable difference in the secretion of mucin fraction IV into the culture medium by ulcerative colitis and control colonic biopsies grown in tissue culture. ${ }^{21}$

Ion exchange chromatography is unlikely to identify small changes in oligosaccharide side chain structure unless they have a marked effect on charge. Lectins, which are non-immune proteins or glycoproteins with specificity of binding for carbohydrates, have proved very useful for detecting subtle changes in the carbohydrate structure of both mucus and mucosal glycoproteins. Expression of fucose (the blood group $\mathrm{H}$ antigen) and galactose 1-3 $\mathrm{N}$ acetyl galactosamine (the Thomsen-Friedenreich or $\mathrm{T}$ antigen) can be detected using respectively the lectins Ulex europaeus 1 (gorse) and Arachis hypogaea (peanut) agglutinin. These blood group antigens, which are expressed in fetal colon, are normally concealed in the adult left colon by the addition of sialic acid or more extensive glycosylation but become revealed as oncofoetal antigens in adenomatous and carcinomatous change $\mathrm{e}^{22} 23$ and are also commonly expressed in ulcerative colitis and Crohn's disease. ${ }^{24} 25$ Similar changes in oligosaccharide side chain structure of mucins are reflected by alterations in $\mathrm{ABO}$ antigen expression in colorectal cancer. ${ }^{26}$ Alterations in antigenicity of colonic mucus in ulcerative colitis have also been revealed using panels of antimucin monoclonal antibodies with differing carbohydrate specificities. ${ }^{27}{ }^{28}$ Similar changes in mucus glycoprotein structure also occur in other epithelial cancers. ${ }^{29}$ Most of these alterations probably reflect reduced sialylation and/or glycosylation rather than synthesis of novel oligosaccharides. The $T$ antigen for example is a common core disaccharide in mucin oligosaccharide side-chains and can be revealed by removing the sialic acid from normal colonic mucus. This shortening of the oligosaccharide side chains is probably a consequence of hyperplasia rather than a premalignant change as the same alterations in lectin binding are found even more consistently in hyperplastic polyps. ${ }^{23}$ The same changes in lectin binding have been reported in the colon of the Cotton Top Tamarin monkey which spontaneously develops both colitis and colonic cancer when kept in captivity. ${ }^{30}$

In colitis and in benign and malignant colonic polyps the same changes in lectin binding tend to affect not only the mucus but also the mucosal glycoproteins. This reflects the presence of mucin-like O-linked oligosaccharide side-chains on the epithelial cell surface glycoconjugates. It is interesting that the $\mathrm{T}$ antigen that becomes abnormally expressed in the colon in inflammatory bowel disease is expressed on normal adult large bile ducts $^{31}$ so it is conceivable that an immune response to the altered antigenicity of colonic glycoconjugates could be a mechanism for sclerosing cholangitis.

\section{Functional consequences of altered cell surface glycoconjugates}

The alterations in epithelial cell surface glycoconjugate structure that occur in parallel with the changes in mucus deserve further attention as they 
may have important functional consequences. Although lectins such as conconavalin A and pokeweed mitogen are well known for their effects on the growth of haemopoietic cells there has been no systematic study of the effects of lectins on the growth of intestinal epithelial cells although the toxic effects of some lectins on the gut - for example, the red kidney bean, are well known. Lectins are particularly abundant in plant seeds which are designed to pass through the intestine intact. The human colon is continually exposed to a wide variety of lectins and if these are capable of modifying growth in the colon the alterations in lectin binding that occur in inflammatory bowel disease and hyperplasia might have important consequences for epithelial cell proliferation. Lectins may also have an indirect effect on cell growth by interacting with growth factors. ${ }^{32}$ For example lectins that interact with mannose (con $\mathrm{A}$ ), galactose (ricin and abrin) or $\mathrm{N}$ acetyl glucosamine (wheat germ agglutinin) all block the binding of epidermal growth factor to cultured human fibroblasts. ${ }^{33}$ The increased risk for cancer in colitis could be caused by growth modulating effects resulting from the altered expression of lectin receptors.

Alterations in cell surface glycoconjugates may also have important consequences for the adherence of pathogens. In this context it is particularly intriguing that the $\mathrm{T}$ antigen (galactose 1-3 $\mathrm{N}$ acetyl galactosamine, the receptor for the peanut agglutinin) that becomes expressed on mucus and surface mucosal glycoproteins in inflammatory bowel disease has recently been shown to be the binding site for Entamoeba histolytica. ${ }^{34}$ This could also explain the well known synergy between amoebae and bacteria in the intestine. The presence of bacteria secreting the appropriate sialic acid Oacetyl esterase and sialidase enzymes would cause desialylation of the surface mucosa and mucus thus revealing the $T$ antigen and allowing adherence of the amoebae. The appropriate studies to confirm or refute this hypothesis have not yet been performed. Similarly the increase in adherent strains of Escherichia coli in ulcerative colitis ${ }^{35}$ and the link between Streptococcus bovis and colonic neoplasia could also be consequences of altered surface carbohydrate expression.

This exciting field is now wide open for further evaluation of the effects that alterations in epithelial cell surface carbohydrate expression exert on epithelial cell growth and the adherence of microorganisms.

University Department of Medicine

JONATHAN M RHODES

and Walton Hospital, Liverpool

\section{References}

1 Rhodes JM, Black RR, Gallimore R, Savage A. Histochemical demonstration of desialation and desulphation of normal and inflammatory bowel disease rectal mucus by faecal extracts. Gut 1985; 26: 1312-8.

2 Mian N, Anderson CE, Kent PW. Effect of O-sulphate groups in lactose and Nacetylneuraminyl-lactose on their enzymic hydrolysis. Biochem J 1979; 181: 387-99.

3 Hoskins LC, Boulding ET. Mucin degradation in human colon ecosystems. Evidence for the existence and role of bacterial subpopulations producing glycosidases as extracellular enzymes. J Clin Invest 1981; 67: 163-72.

4 Hoskins LC, Agustines M, McKee WB, Boulding ET, Kriaris M, Niedermeyer G. Mucin degradation in human colon ecosystems. Isolation and properties of fecal strains that degrade $\mathrm{ABH}$ blood group antigens and oligosaccharides from mucus glycoproteins. J Clin Invest 1985; 75: 944-53.

5 Corfield AP, Williams AJK, Clamp JR, Wagner SA, Mountford RA. Degradation by 
bacterial enzymes of colonic mucus from normal subjects and patients with inflammatory bowel disease: the role of sialic acid metabolism and the detection of a novel O-acetylsialic acid esterase. Clin Sci 1988; 74: 71-8.

6 Rhodes JM, Gallimore R, Elias E, Allan RN, Kennedy JF. Faecal mucus degrading glycosidases in ulcerative colitis and Crohn's disease. Gut 1985; 26: 761-5.

7 Rhodes JM, Gallimore R, Elias E, Kennedy JF. Faecal sulphatase in health and in inflammatory bowel disease. Gut $1985 ; 26$ : 466-9.

8 Rhodes JM, Black RR, Gallimore R, Savage A. Histochemical demonstration of desialation and desulphation of normal and inflammatory bowel disease rectal mucus by faecal extracts. Gut $1985 ; 26$ : $1312-8$.

9 Greco V, Lauro G, Fabrini A, Torsoli A. Histochemistry of the colonic epithelial mucins in normal subjects and in patients with ulcerative colitis. A qualitative and histophotometric investigation. Gut 1967; 8: 491-6.

10 Ehsanullah M, Filipe MI, Gazzard B. Mucin secretion in inflammatory bowel disease: correlation with disease activity and dysplasia. Gut 1982; 23: 485-9.

11 Reid PE, Culling CFA, Dunn WL, Ramey CW, Clay MG. Chemical and histochemical study of normal and discased human gastrointestinal tract. A comparison between histologically normal colon, colonic tumours, ulcerative colitis and diverticular disease of the colon. Histochem J 1984; 16: 235-51.

12 Burke DA, Clayden SA, Dixon MF, Axon ATR, Lacey RW. Oral tobramycin improves the outcome of acute ulcerative colitis [Abstract]. Gut 1987; 28: A1390.

13 Clamp JR, Fraser G, Read AE. Study of the carbohydrate content of mucus glycoproteins from normal and diseased colons. Clin Sci 1981; 61: 229-34.

14 Gold DV, Miller F. Comparison of human colonic mucoprotein antigen from normal and neoplastic mucosa. Cancer Res 1978; 38: 3204-11.

15 Podolsky DK, Isselbacher KJ. Composition of human colonic mucin. Specific alterations in ulcerative colitis. Gastroenterology 1983; 72: 142-53.

16 Podolsky DK, Isselbacher KJ. Glycoprotein composition of colonic mucosa. Specific alterations in ulcerative colitis. Gastroenterology 1984; 87: 991-8.

17 Raouf AH, Parker N, Iddon D, Rhodes JM. Lack of selective mucin subclass depletion in ulcerative colitis. Clin Sci 1989; 76: 27P.

18 Rhodes JM, Parker N, Ching CK, Patel P. Mucin subclasses in ulcerative colitis [Letter]. Gastroenterology 1987; 93: 435-7.

19 Lamont JT, Ventola A. Purification and composition of colonic epithelial mucin. Biochim Biophys Acta 1980; 626: $234-43$.

20 Cope GF, Heatley RV, Kelleher J, Axon ATR. In vitro mucus glycoprotein production by colonic tissue from patients with ulcerative colitis. Gut 1988; 29: 229-43.

21 Smith AC, Podolsky DK, Biosynthesis and secretion of human colonic mucin glycoproteins. J Clin Invest 1987; 80: 300-7.

22 Boland CR, Montgomery CK, Kim YS. Alterations in human colonic mucin occurring with cellular differentiation and malignant transformation. Proc Natl Acad Sci USA 1982; 79: 2051-5.

23 Rhodes JM, Black RR, Savage A. Glycoprotcin abnormalities in colonic carcinomata, adenomata, and hyperplastic polyps shown by lectin peroxidase histochemistry. $J$ Clin Pathol 1986; 39: 1331-4.

24 Boland CR, Lance P, Levin B, Riddell RH, Kim YS. Abnormal goblet cell glycoconjugates in rectal biopsies associated with an increased risk of neoplasia in patients with ulcerative colitis: early results of a prospective study. Gut 1984; 25 : 1364-71.

25 Rhodes JM, Black RR, Savage A. Altered lectin binding by colonic epithelial glycoconjugates in ulcerative colitis and Crohn's disease. Dig Dis Sci 1988; 33: 1359-63.

26 Yuan M, Itzkowitz SH, Palekar A, Shamsuddin AM, Phelps PC, Trump BF, Kim YS. Distribution of blood group antigens A, B, H, Lewis ${ }^{\mathrm{a}}$ and Lewis ${ }^{\mathrm{h}}$ in human normal, fetal, and malignant colonic tissue. Cancer Res 1985; 45: 4499-511.

27 Podolsky DK, Fournier DA. Emergence of antigenic glycoprotein structure in ulcerative colitis detected through monoclonal antibodies. Gastroenterology 1988; 95: 371-8.

28 Podolsky DK, Fournier DA. Alterations in mucosal content of colonic glycoconjugates in inflammatory bowel disease defined by monoclonal antibodies. Gastroenterology 1988; 95: 379-87.

29 Ching CK, Rhodes JM. Identification and partial characterisation of a new pancreatic cancer related glycoprotein by SDS-PAGE and lectin blotting. Gastroenterology 1988; 95: $137-42$.

30 Boland CR, Clapp NK. Glycoconjugates in the colons of new world monkeys with 
spontaneous colitis. Association between inflammation and neoplasia. Gastroenterology 1987; 92: 625-34.

31 Rhodes JM, Hubscher S, Black R, Elias E, Savage A. Lectin histochemistry of the liver in biliary disease, following transplantation and in cholangiocarcinoma. J Hepatol 1988; 6: $277-82$.

32 Feizi T, Childs RA. Carbohydrate structures of glycoproteins and glycolipids as differentiation antigens, tumour-associated antigens and components of receptor systems. Trends Biochem Sci 1985; 10: 24-9.

33 Carpenter G, Cohen S. Influence of lectins on the binding of ${ }^{125}$ I-labelled EGF to human fibroblasts. Biochem Biophys Res Commun 1977; 79: 545-52.

34 Chadee K, Johnson ML, Orozco E, Petri WA, Ravdin JI. Binding and internalization of rat colonic mucins by the galactose/N-Acetyl-D-Galactosamine adherence lectin of Entamoeba histolytica. J Infect Dis 1988; 158: 398-406.

35 Burke DA, Axon ATR. Ulcerative colitis and E. coli with adhesive properties. J Clin Pathol 1987; 40: 782-6. 